\title{
Perspectives on the European economic and social model: distributional and institutional conflicts
}

\author{
Marius R. Busemeyer
}

Max Planck Institute for the Study of Societies

Paulstr. 3, 50676 Cologne, Germany

E-mail: busemeyer@mpifg.de

\section{Christian Kellermann*}

International Policy Analysis Unit

Friedrich Ebert Foundation

Hiroshimastr. 17, 10785 Berlin, Germany

E-mail: Christian.Kellermann@fes.de

*Corresponding author

\section{Alexander Petring}

Research Unit 'Democracy: Structures, Performance, Challenges'

Social Science Research Center Berlin

Reichpietschufer 50, Berlin, Germany

E-mail: petring@wzb.eu

\section{Andrej Stuchlík}

Freie Universität Berlin

Jean Monnet Centre of Excellence

Ihnestr. 56, 14195 Berlin, Germany

E-mail: anstuchlik@web.de

\begin{abstract}
Where are the fields of consensus and divergence in the positions of social democratic parties in Europe concerning the European Economic and Social Model (EESM)? Building on the findings of a Europe-wide survey, this article analyses patterns of social and economic policy preferences along country-group specific clusters. While consensus among centre-left parties concerning the general problem perception is rather strong, there is very little common ground on the level of actual problem-solving policies. This divergence can be explained by the dominance of 'national' interests over the general party-political agenda. These national interests are shaped, on the one hand, by interstate distributional conflicts, and, on the other hand, by the degree of approximation of one's own welfare state model to the model of the 'core European states' - the implicit blueprint of the EESM.
\end{abstract}

Keywords: European Economic and Social Model; EESM; social democratic parties; welfare state regimes; varieties of capitalism.

Konstanzer Online-Publikations-System (KOPS)

URL: http://nbn-resolving.de/urn:nbn:de:bsz:352-0-375011

Copyright (C) 2008 Inderscience Enterprises Ltd. 
Reference to this paper should be made as follows: Busemeyer, M.R., Kellermann, C., Petring, A. and Stuchlík, A. (2008) 'Perspectives on the European economic and social model: distributional and institutional conflicts', Int. J. Public Policy, Vol. 3, Nos. 1/2, pp.39-57.

Biographical notes: Marius R. Busemeyer is a Research Associate at the Max Planck Institute for the Study of Societies in Cologne, Germany, focusing on topics of economic, education and social policy. Previously, he worked as a Researcher at the University of Heidelberg.

Christian Kellermann is a Research Fellow in the International Policy Analysis Unit at the Friedrich-Ebert-Stiftung in Berlin, Germany, focusing on European economic and social policies.

\footnotetext{
Alexander Petring is a Research Fellow in the research unit 'Democracy: Structures, Performance, Challenges' at the Social Science Research Center Berlin, Germany.

Andrej Stuchlík is a $\mathrm{PhD}$ student at Freie Universität Berlin, focusing on topics of social security reform. Previously, he worked as a Lecturer at the Andrássy-University in Budapest, Hungary.
}

\section{Introduction ${ }^{1}$}

In recent decades, the course of European integration has resulted in a profusion of supranational structures and regulations. With the enlargement rounds, the degree of heterogeneity of the members of the union has also increased. As regards the EU-25, its economies are divergent, not solely in terms of performance and efficiency - for example, in respect of resource allocation - but also, and significantly, in terms of economic constitution, forms of organisation and distribution of income. This is why political parties are under increasing pressure to produce a Europe-wide consensus on policy measures.

This paper concentrates on the standpoints of social democratic parties towards the European Economic and Social Model (EESM). The basis of the study is a survey in which a total of 50 questions were put to over 100 leading personalities from social democratic parties, trade unions, ministries, parliaments and employer organisations in 17 countries. The questions were grouped into three thematic areas:

1 economic policy

2 social policy

3 competition (amongst the member states). ${ }^{2}$

Two key questions formed the primary focus:

1 In which areas are agreement/divergence to be found in the standpoints of social democracy?

2 How can we explain these common standpoints and differences? 
Based on a brief outline of the broad concept of EESM, Section 2 presents the main argument of the paper: we draw on various welfare state concepts/models and propose to analyse possible integration by splitting the distributional effects of European policy measures into two dimensions:

1 interstate redistribution

2 the struggle over different levels of harmonisation.

The latter can be conceived as an institutional conflict between the continental core EU member states and competing welfare regimes. Hence, we propose a set of four welfare regimes in terms of which to analyse member states' preferences regarding European social policy: 'Eurosceptics', 'Transition countries', 'Cohesion states' and 'Old Europe'. Section 3 offers the standpoints of the 17 social democratic parties with respect to concrete proposals for EESM reform. There follows an analysis of the findings with regard to how compelling are the explanations of various effects of distribution for diverging viewpoints across the European social democratic parties (Section 4), with a brief conclusion to round off (Section 5).

\subsection{The European economic and social model}

There is a controversy as to whether it is possible to talk of one EESM. As a rule, this debate is based on two different points of reference: advocates emphasise a sociopolitical consensus that is said to prevail in all European countries, and sets the EU apart from the USA. Sceptics see in the numerous national social-model variants a major obstacle to a common model and reject this both as a category and as a goal. European integration so far has shown that there is particular opposition to the delegating of welfare state responsibilities. This is reflected in the comparatively underdeveloped sociopolitical responsibilities of the union, which, since the inclusion of the Social Chapter in the Amsterdam Treaty, have nevertheless been broadened incrementally. In addition, increased social policy coordination, though not harmonisation, has taken place within the framework of the open method of coordination since 2000 (O'Connor, 2005). In this way, the EESM has remained the subject of ongoing political dispute.

\section{Theoretical framework}

\subsection{Party interests and ideologies}

Most studies of national parties' standpoints on European issues have provided support for the hypothesis of the 'hump-shaped curve'. This hypothesis implies that the parties on the left and on the right of the party spectrum tend to represent Eurosceptic viewpoints, whilst the parties in the centre represent pro-integration stances (for example, Hix, 1999; Hooghe et al., 2002; Hooghe and Marks, 2004). Within the parties relatively close to the political centre, further differentiations are possible. Conservative players as "the creation and opening up of markets" first supported European integration (Marks, 2004, p.236). Hooghe and Marks accept that, over the past 20 years, progress in integration towards European minimum standards, infrastructure and redistribution have tended to be accepted more by centre-left players (Hooghe and Marks, 2004, 9f.; Dauderstädt, 2004, p.13). This is why there has been a change of preferences by parties at the centre of the 
left-right party spectrum: at the beginning of the twenty-first century, centre-left parties were more likely to espouse a stronger preference for progressive European integration than centre-right parties were.

If European social democrats had a uniform viewpoint, irrespective of the various institutional and political preconditions prevailing in the various EU member states, then party reasoning would dominate institutional differences as well as national interests. This is in line with standard Partisan Theory. Its core argument is relevant to a comparison of the standpoints of left and right parties. This has been explained by the fact that differences in the (objective) interests and (subjective) preferences of voters are reflected in the (government) policy of the parties they vote for (Hibbs, 1977; see also Schmidt, 1983; Cameron, 1985; Budge and Keman, 1990; Boix, 1998). If the hypothesis concerning the link between party-political agendas and the socioeconomic interests of their electorate is valid, we should identify a high level of uniformity when comparing the standpoints of social democrats from various countries.

However, testing for consensus, the degree of abstraction of each issue is significant. On an abstract and general level, there is a tendency to expect greater uniformity of viewpoints. On the one hand, this is because there is rhetoric about agendas rather than actual political action. On the other hand, the more concrete the issue or policy proposal under discussion, the more prominent the differences in the makeup of the current national electorate groups as well as the divergences in interests reflected in the respective institutional environment. Therefore, the following hypothesis can be put forward:

\section{H1 A high level of uniformity in the standpoints of European social democrats can} be expected:

- if the interests of the national electorate groups are affected in the same way

- if questions are posed at an abstract, 'agenda' level.

\subsection{Distributional conflicts: redistribution versus institutional conflicts}

If dissent and not uniformity is observed in European social democracy, then it should be supposed that the driving forces are perceived or real redistributional conflicts as well as institutional conflicts. Consequently, these conflicts unfold in two dimensions:

1 Redistribution: Differences in respect of economic prosperity influence viewpoints on various EU policies and thereby uniformity/divergence. This effect is manifest mainly in respect of policy fields linked to redistribution amongst states. Examples include the structural and cohesion funds and the Common Agricultural Policy. Divergence of viewpoints amongst social democrats on these policy fields would show that national interests, defined mainly in terms of interstate redistribution, are a dominant factor in the party-political interest in a uniform viewpoint, or rather in transnational European solidarity. What is to be expected is that social democrats in 'rich' countries tend to want to reduce the extent of interstate redistribution. This is not the least because the funds flowing out to Brussels restrict the capacity of social democratic governments to implement intrastate redistribution policy. Social democrats in rather 'poor' countries, on the other hand, want to maximise the extent of interstate redistribution as it is chiefly they who are the beneficiaries of these measures. ${ }^{3}$ 
2 Institutional conflicts: Attempts so far to conceptualise the different effects of the stages of European integration on EU countries have, on the one hand, drawn the distinction mainly between 'poor' and 'rich' (or rather those with weak and strong regulations) member states, and, on the other hand, between uniform European regulations at a high and low level of protection (for example, Scharpf, 1996; 2000, 144ff). In the process, it has been assumed simplistically that European (minimum) standards are the only relevant form of European integration. In order to alleviate competitive pressure, rich or highly regulated countries accordingly have an interest in high European standards, as this enables them to reduce and restrain competitive pressure emanating from the new member states with their lower standards. The new member states, on the other hand, will tend to reject such efforts at harmonisation, as these efforts would result in their losing their comparative advantages, possibly hindering their catching up.

Yet by way of demarcating and continuing Scharpf's arguments, this second dimension does not provide us with a measure of the level of harmonisation as such, but rather the degree of resemblance in relation to the Economic and Social Model (ESM) prevailing in the countries of continental Europe. In general, the essential aspects of the framework of the current and effective EESM have emerged on the basis of the conditions prevailing in the states of the 'EU core' (the six founding members: Belgium, the Netherlands, Germany, France, Italy and Luxembourg). A willingness to become involved with further stages of integration is closely linked to it. If the EESM resembles the model of one's own country, a warmer welcome is likely for integration because transposing the model to the EU level safeguards the survival capability of one's own national model. If, however, closer convergence with the EESM were to entail extensive transformation of one's own model, more reluctance could be expected.

Consequently, a number of aspects can be subsumed under this second axis. This also has consequences regarding the obstacles to setting up a common EESM. On the one hand, the axis indicates the extent to which the level of regulation deviates from the level in the states of continental Europe, and thereby from the level of harmonisation most likely to be expected from common EU regulation. Of course, British social democrats differ from their Scandinavian counterparts, yet the crucial factor is that what we label institutional conflicts are rather distributional conflicts about the level of harmonisation to be attempted than a matter of rivalry between the respective welfare regimes.

The different levels of harmonisation result from the diversity of EEMs. In the process, the various welfare regimes function as 'filters' as regards European policy and should lead to various 'outcomes' where 'inputs' are identical (Dauderstädt, 2004, p.6). Esping-Andersen's $(1990 ; 1996)$ major classification, with its tripartite division into 'liberal', 'social democratic/Scandinavian' and 'conservative' welfare states, is aimed at the degree of decommodification: that is, the extent to which areas of social life are excluded from free market mechanisms for the protection of the citizens (see Table 1). Later comparative studies considered the tripartite division as too rigid and added two supplementary ideal types (Castles and Mitchell, 1993; Goodin et al., 1999; Leibfried, 1991), with the states of central and eastern Europe and the Mediterranean countries representing independent types in particular. The former link a redistributive 'communist legacy' with strongly liberal reform policies (in part) during the process of transformation (McMenamin, 2004). 
Table 1 Typology of welfare states, selected EU member states

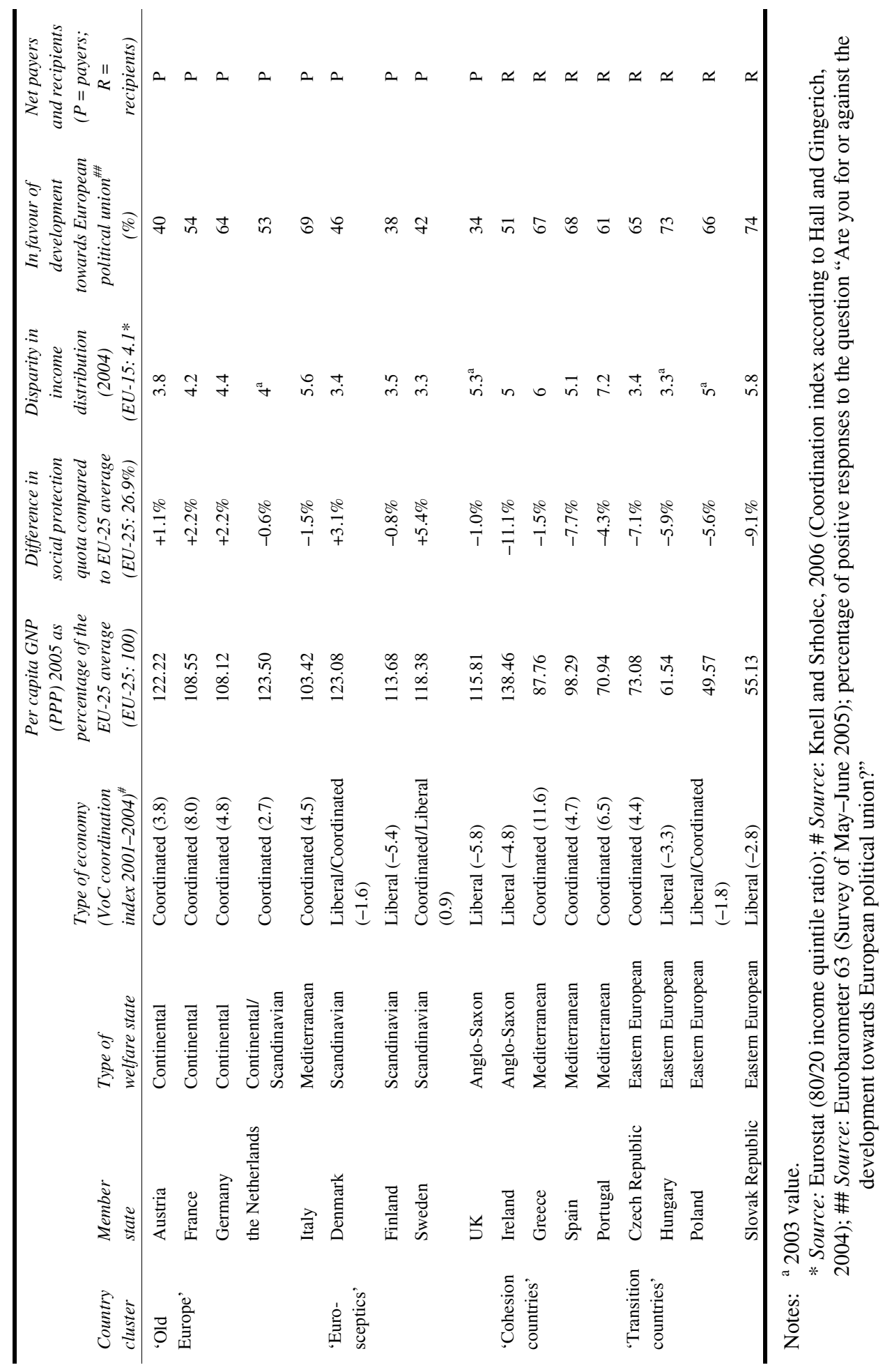


Another attempt to create a welfare state typology, but with greater emphasis on economic systems, was the 'Varieties of Capitalism' approach. Its proponents pursued the idea of two ideal types: Coordinated Market Economies (CME) and Liberal Market Economies (LME) (Hall and Soskice, 2001b). While LMEs coordinate their economic activities primarily via hierarchies and markets, CMEs depend more strongly on non-market relations (informal contracts, networks, and so on), and thereby on the strategic behaviour of market players (Hall and Soskice, 2001a, 8ff.).

Based on the above typologies and selected indicators, five classical types of welfare states can be formed:

1 the continental European member states, with a relatively high degree of decommodification, comparatively low disparity of incomes, and coordinated economic systems

2 the Scandinavian member states, with very high effects of decommodification, very low disparity of incomes, and weaker coordination of economic systems

3 the Anglo-Saxon member states, with low effects of decommodification, comparatively high disparity of incomes, and liberal economic systems

4 the Mediterranean member states, with medium effects of decommodification, greater disparity of incomes, and coordinated economic systems

5 the central and eastern European member states, with low effects of decommodification, comparatively low disparity of incomes, and a tendency towards liberal economic systems (see Table 1).

Based on these two dimensions of integration - and thus two lines of possible conflict - we observe a slightly different picture from the classical welfare regime cluster: the countries investigated can now be regrouped as in Table 2:

Table 2 Distributional conflicts over integration: redistribution versus institutional conflict

\begin{tabular}{lll}
\hline \multirow{2}{*}{$\begin{array}{l}\text { Second dimension: Closeness to EU } \\
\text { core economic and social model }\end{array}$} & \multicolumn{2}{l}{ First dimension: Demand for interstate redistribution } \\
\cline { 2 - 3 } & Low & High \\
\hline Low & 'Eurosceptics' & 'Transition countries' \\
& (GB, DK, S, FIN) & (CZ, PL, H, SK) \\
High & 'Old Europe' & 'Cohesion countries' \\
& (D, F, NL, A, I) & (IRL, E, GR, P) \\
\hline
\end{tabular}

In this picture, the initial position of a country with respect to demand for redistribution amongst states and the degree of convergence of one's own ESM with the ESM of the European core define each group of countries. Each cluster will display similar positions with regard to the institutionalisation of a common EESM, the continuation of the process of European integration, and the harmonisation of standards at EU level and at high level.

The Old Europe group of states (Germany, France, the Netherlands, Austria and Italy) constitutes the initial position here. They have an interest in ongoing European integration and in creating a common standard at a high level as they hope, as a result, to safeguard the survival capability of their own ESM, especially when confronted with the 
competitive pressures of an EU that is becoming heterogeneous. At the same time, they have only a slight interest in expanding interstate redistribution policy because, as comparatively affluent states, they would have to deliver the most funds.

The group of Eurosceptic countries (UK, Denmark, Sweden and Finland) likewise has an interest in minimising interstate redistribution because, as net payers, they too are involved in financing redistribution to a considerable extent. As far as the second dimension is concerned, the expectation from the 'classic' Scharpf perspective, at least for the Scandinavian countries, would be an interest in regulation and harmonisation at a high level, as this could mitigate competitive pressure. However, our argument is that it does not depend only on the level of harmonisation - which at any rate is difficult to determine - but mainly on the concrete institutional structuring of regulations against a background of variants of capitalism and various types of welfare.

What the Scandinavian states have to fear from the institutionalisation of a common EESM is damage to the operability and integrity of their own model. A similar situation applies, though under different circumstances, to the liberal market economy of Great Britain. It is because of this that these Eurosceptic countries are more mindful of preserving the operability of their own ESMs. To shift members from the Eurosceptic group in the direction of Old Europe - which tends to welcome integration - will only be possible if the gain in benefits from the 'Scharpf effect' of reduction in competitive pressure through enhanced regulation is greater than the loss which stems from surrendering areas of national autonomy. This is possible especially with policy fields, which do not affect the core elements of the current national model.

As the main beneficiaries of interstate redistribution for some time to come, the group of central and eastern European Transition states will obviously prefer such policies. Their economic systems, with their liberal tendencies and a comparatively low degree of decommodification, also testify to the fact that these states are relatively far removed from the welfare state model of core Europe. Therefore, these countries would fear forfeiting economic competitive advantages arising from low wages and low rates of taxation. Hence, the question arises: To what extent is it possible to gain the approval of these states concerning the establishment of high-level common standards and the institutionalisation of a common EESM? To some extent the situation mirrors that which prevails in the Eurosceptic countries: the net gain of an interstate redistribution policy must be high enough to compensate for the benefits forfeited owing to loss of competitive advantages.

The situation is somewhat different in the group of Cohesion states. Until very recently, these also benefited greatly as a result of interstate redistribution policy. However, they have a greater affinity to the ESM of core Europe. This applies to the Mediterranean states (Spain, Portugal and Greece) who, depending on the development of economic principles, manifest a medium degree of decommodification, though comparatively coordinated market economies. However, this also applies to Ireland, which differs from the ideal-typical Anglo-Saxon model (Daly and Yeates, 2003) because of the expansion of mechanisms for coordinating the market economy (for example, social pacts between employers and trade unions). In this way, only Great Britain, as a representative of the Anglo-Saxon model, remains a liberal market economy within the EU. The group of Cohesion states can hope for improvements in the sociopolitical situation in their own countries as a result of the expansion of social policy at EU level and the institutionalisation of a common EESM. This is a strong reason for social democrats in these countries to support this project. 
What is the link between the division of groups of countries presented in the matrix and the central question? Our hypothesis is that the country interests identified through the two dimensions mentioned can explain the divergence of viewpoints in respect of the EESM.

National interests, which are determined by the viewpoint taken by a country with regard to interstate redistribution policies on the one hand, and by the institutional exigencies of the respective welfare production regime on the other, are dominant factors governing party-political interest in social democratic unity at EU level.

H2 The standpoints of social democratic parties will diverge if national interests dominate party-political interest. National interests are shaped by the demand for redistribution policies, as well as the institutional structure of the respective welfare regime.

\section{Social democratic viewpoints on the EESM}

This section presents the viewpoints of social democratic parties in the three domains of the economy, social policy and competition, with an evaluation of the current EESM and tangible reform proposals.

\subsection{The economy}

The social democrats are unanimous on the need for reform of the Stability and Growth Pact (SGP) (with the exception of the UK and Ireland). Most parties favoured a differentiated approach to investment as a means of countering inflexibility, along with a greater orientation towards economic growth. This higher consideration of public investment is found amongst a relative majority of respondents. In some countries, however, further change to the SGP is rejected in favour of greater pressure for preservation of the rules of member states (Finland, Poland, the Slovak Republic). Italy, Greece and Ireland propose linking with the aims of the Lisbon Strategy. These reform proposals embody various viewpoints, chiefly amongst countries or groups of countries where continental and southern European social democrats count amongst the most ardent supporters of investment, while centre-left parties in the central and eastern European states advocate the introduction of so-called structural deficits.

We observed the converse scenario concerning reform of the European Central Bank (ECB) mandate. Majority of social democrats are opposed to a new weighting in favour of economic aims, and assess the work undertaken by the ECB as predominantly good (with the exception of Old Europe, where a rather mixed assessment prevails). Accordingly, the wish for a higher inflation target is most prevalent among the new member states.

In addition to fiscal and monetary policy, wages and salaries are key. Therefore, the call for stronger coordination of incomes policy at the European level is frequently heard. Although the majority rejects this as a matter of principle, disparities between countries are considerable. We found a majority favouring EU-wide coordination of incomes policy only within the continental group of Old Europe. On the other hand, the 
Eurosceptics reject this idea. For the large majority of social democrats in the other countries, wages should be negotiated at the national level, while solely in eastern Europe does the sectoral level have priority.

The proposal for greater coordination of employment policy meets with mixed approval, as the majority rank national influence on European employment strategy as too weak. Greater coordination finds broad support with Transition countries and especially Old Europe. However, Eurosceptics are particularly against such a proposal.

Besides the reforms cited to existing institutions, there are also demands for new instruments of EU economic policy. Still relatively near the status quo is the proposal to supplement the 'Integrated Guidelines"4 with a rather short-term coordination perspective. Such a short- to medium-term control mechanism is advocated particularly by continental countries, while the others are indifferent on this point.

In contrast to the change/supplementing of general economic policy coordination via reports, EU anticyclical measures would be a totally new instrument of economic policy, finding support only with the Cohesion countries, while the Eurosceptics are reluctant, expressing clear opposition to EU anticyclical measures. ${ }^{5}$ The reason cited was the rejection of a growing EU budget, which would be the necessary precondition for such a proposal. A transfer of responsibility for economic policy (especially fiscal and incomes policy) to the EU level is roundly rejected there, with voluntary coordination of 25 countries, on the other hand, being assessed as unrealistic.

\subsection{Social policy}

A majority of the social democratic parties questioned reject working towards a European social model in the long term, or rather regard this as unrealistic at best. Instead of this, there is agreement on 'social minimum standards' or 'social entitlements' at the European level. Within this framework, variations at national level could unfold. The divergent approval of central and eastern European states concerning a long-term project for an EESM can be explained in terms of their economic goal of catching up.

However, it remains relatively unclear at this point which 'social standards' are meant. The growing resistance to more concrete proposals can be illustrated with the example of the minimum wage. Approval of the introduction of a European minimum wage fluctuates significantly depending upon the group of countries under consideration. However, left-leaning parties and trade unions in the Eurosceptic countries voice unanimous opposition. In these countries, the view prevails that regulation of the minimum wage should be the preserve of business and labour. Statutory intervention would weaken the position of business and labour. Just as critical are the members of Old Europe, especially as here, too, trade unions in countries with strong social partnerships (Austria, though also France) reject intervention in wage matters by legislators or even by the EU. Besides this, country-specific minimum wage arrangements are most advantageous for the Cohesion countries. The majority of central and eastern European states expressed support for an EU-wide minimum wage, though at country-specific levels (for instance, according to GDP per capita).

As already mentioned, a positive attitude prevails amongst social democrats in Europe towards the institution of social dialogue and collective wage agreements, even if institutionalisation at the EU level and the results so far receive a mixed assessment. Nevertheless, a broad majority of social democratic parties in Europe advocate that 
management and labour should play a greater part in the EU in future. However, they disagree on the measures by which this should be achieved: A large majority of social democrats called into question a greater role for the commission, which is said to allocate 'contracts' for quasi-legal dealing to business and labour, as well as exerting more pressure on employers to induce a more cooperative attitude. While social democrats in the central and eastern European states would like to grant the commission greater influence, there are more reservations in the Eurosceptic countries. ${ }^{6}$

\subsection{Competition}

In the realm of competition, two issues matter most:

1 tax competition, which, as a result of EU enlargement, has come more into the limelight

2 the problem of liberalising service markets. Policies here aim at preventing a detrimental 'race to the bottom'.

There exist huge differences concerning how to deal with (perceived) tax competition. The introduction of the majority principle in the Council of Ministers on tax issues - a relatively pragmatic-institutional solution - finds no majority. If some social democratic parties, as in Finland, express support for such a reform approach, it is with the reservation of establishing clear boundaries for EU responsibilities on taxation issues. Only Old Europe and some of the Cohesion countries support such a move towards qualified majority voting. While the Scandinavians hold no uniform viewpoint, the Eurosceptics and the Transition countries clusters are clearly opposed to this.

The social democratic parties are just as divided on whether the tax responsibility of the EU Commission should be increased. While the Eurosceptic social democrats voiced clear opposition to such a measure in the context of tax competition, the eastern Europeans in particular showed themselves open to this option. In a somewhat diluted form, this also applies to Old Europe and the Cohesion countries. ${ }^{7}$

The key reform options concerning Europe-wide tax competition are the introduction of a minimum rate for company tax and the harmonisation of the basis of tax assessment. A majority of social democratic parties in Europe express support for the regulation of company taxation, even if a range of parties concentrate initially on the standardisation of the tax base. The harmonisation of the basis of tax assessment is often understood to be a pragmatic starting point for ongoing integration. This point can then be followed, by way of further development, by the introduction of a 'band' (margin), according to the Austrian social democrats, for example. The Italian social democrats even want to financially compensate (for example, via structural funds) the new member states for possible loss of competitiveness arising from any tax harmonisation. In the eastern European transition countries, the centre-left parties likewise advocate the introduction of tax corridors in order to prevent competition by undercutting. ${ }^{8}$

Additionally, they view the idea of an EU tax for establishing a direct relationship between the EU and the electorate as a likely alternative or compensation.

In sum, only social democratic parties in Old Europe clearly favour the introduction of minimum company taxation. However, although the Cohesion countries display a rather mixed attitude on this issue, we find a clear inclination towards harmonising the tax base even within the Eurosceptic and Transition clusters. 
Another facet in the domain of competition amongst the member states is the liberalisation of services in general and the Bolkestein Directive in particular. Amongst the social democratic parties in Europe, there is no general rejection of a liberalisation of the service market. Social democrats especially in central and eastern Europe see service competition as a necessary development of the internal market favouring real catching up. However, within the social democratic camp there is widespread opposition to the country-of-origin principle because of the expected 'race to the bottom', which would be detrimental to the community as a whole. Such competition in terms of social provision, the environment and labour rights is feared in all our welfare clusters except in the Transition countries. Their position is slightly different, as became clear with the acceptance of the compromise proposals of the European Parliament. When acknowledging the unanimity of European social democracy's rejection of the country-of-origin principle, it must not be misunderstood that this is a defensive project safeguarding the vested interests of the welfare state as well as the constructive institutionalisation of an effective EU social policy.

Concerning alternatives or additions to the directive, most parties voiced a clear plea for separate treatment of public services. These include the education and care sector, among other things. A dutiable goods list would have to be standard and may not be specified individually by member states. In most cases, the alternative concept of the host-country principle finds support amongst the parties of the left.

Amongst the left-wing parties in Europe, what prevails is the opinion that, while the new eastern European development regions should receive structural funds, at the same time (in parallel with the CAP) no increase in the overall budget is envisaged, with old development regions scheduled to drop out of the programme (according to, for example, the Swedish social democrats). Only selected countries, such as France, Ireland or Denmark, suggest building up the funds for structural and cohesion policy, among other things by increasing UK contributions. The social democrats unanimously prefer the region-specific approach (with the exception of large-scale infrastructure tasks, which are to be organised by the state), as this is said to contribute to 'depoliticisation'. Interviewees in Transition countries in particular criticised the fact that regional and structural policies are based on excessively formal application processes and an opaque and complicated system, with too little time made available for sound appraisal.

\section{Analysis and discussion}

As expected, there is a high degree of unanimity at an abstract level amongst a relatively large number of viewpoints: a broad consensus predominates, for example, in respect of the need to reinforce the social dimensions of the EU, with criticism of the rigidity of the SGP and positive evaluation of the institution of social dialogue. However, the more concrete the policy proposals, the sooner schisms and differences come to light.

As already explained, our results can be evaluated from two aspects:

1 If a high degree of unanimity can be observed on a given viewpoint, then party interests are more important than national interests.

2 Conversely, if a high degree of disagreement is observed, it can be argued that the interests of countries dominate the common party-political interest in creating a uniform supranational policy viewpoint. 
Thus, conflicting preferences originate from the institutional arrangements of welfare regimes on the one hand, and from perceived and real redistributional conflicts of an interstate kind on the other.

\subsection{The economy}

Unanimity prevails at the level of general problem perception, although this consensus becomes relative where concrete reform proposals are involved. As regards reform of the SGP, the proposal for a differentiated approach to investments finds a majority; proposals for links with the aims of the Lisbon Strategy (that is, allocating resources for achieving the Lisbon aims) would additionally be compatible with this proposal.

Concerning concrete measures aimed at greater coordination of economic policies, only a few social democratic parties have a definitive opinion. ${ }^{9}$ Here the cornerstones of the current nation-state economic models are touched upon: the options range from the liberal economic policy conducted in the UK, through the model of state-centred coordination with gourvernement économique (France), to models in which management and labour play a principal role (Austria, Scandinavia, and, to a limited extent, Ireland). Consequently, a majority of respondents regard the benefits of a coordinated economic and fiscal policy as fewer than the costs of reducing national decision-making autonomy.

More prominent are the differences between groups of countries in respect of coordinating wage policy. Countries differ systematically according to welfare clusters: The Eurosceptic countries reject the proposal for closer coordination of wage policy. Nevertheless, fewer distribution coalitions can be ascertained, although there are coalitions along the dichotomy spectrum of coordinated versus liberal market economies. This is manifested, for example, by the question of the preferred level for tariff negotiations. The sole advocates of EU-wide sectoral coordination are found amongst CMEs, whereas LMEs express support for wage settlements at enterprise level or wish to preserve their national structures. Because the fundamental characteristics of tariff systems are fundamentally affected here, institutional convergence or the institutionalisation of wage negotiations at EU level cannot be expected in the short term. The question of wage policy affects the cornerstones of the Scandinavian and the British models, the ones furthest from the EU core. The respondents view the benefits of reduced wage pressure from eastern Europe through an EU-coordinated wage policy as insufficient to justify the loss of autonomous negotiation.

Consequently, unanimity prevails on economic policy at an abstract level. If the development of efficient policy instruments tends to be improbable as regards wage policy, the obstacles to coordinating economic and business cycles in Europe appear to be somewhat lower.

\subsection{Social policy}

Strengthening the social dimension of the EU has to deal with one problem: most actors reject a standard social model (with the exception of the Transition cluster) and by contrast, appreciate the heterogeneity of European welfare states. These findings clearly show the extent to which the institutional structure of the welfare regime - or rather the expected pressure to adapt to the hegemonic continental European welfare model through coordination and nationalisation - shapes the preferences of political parties. Some 
respondents proposed unification with social minimum standards or social entitlements, but common minimum standards already exist de facto and social entitlements are set down in the Social Charter of 1961 and 1989, and in the Charter of Fundamental Rights of 2000. However, this did not lead to a fundamental sociopolitical EU agenda, as this would require unanimity to achieve common goals concerning the welfare state.

As regards concrete proposals, the conflicts are more prominent in the domain of social policy than in that of economic policy. The issue of the European minimum wage shows this in an exemplary way: While the Eurosceptic states are against this proposal, opponents and advocates of a country-specific minimum wage balance each other out in Old Europe. On the other hand, the majority of social democrats in the Cohesion states are in favour of country-specific regulation. In sum, those countries are the clearest opponents, in which the expected downward pressure to adapt turns out to be greatest. This pressure to adapt by implementing a country-specific minimum wage involves not so much the wage levels as the institutional costs of adaptation because, in the states with a developed partnership of management and labour, the respondents believe that wage policy issues should be regulated not by the state but within the framework of management and labour. Consequently, here too, we observe institutional conflicts between the Scandinavian welfare regime and the EU core states of Old Europe.

On the other hand, a high degree of unanimity was shown in support of social dialogue and strengthening the role played by management and labour. Here too are differences, for example concerning whether strengthening the social dialogue must be brought about mainly by employers and employees themselves or whether the commission can intervene in a supportive capacity through institutional reforms. Most respondents supported the latter. The collective organisation of labour relations was repeatedly highlighted by a number of respondents as being an important constituent of the current 'European social model'.

\subsection{Competition}

Similarly, there is potential for action for curtailing tax competition that would be detrimental to the common good, at least concerning company taxes. This is in line with our argumentation above: Tax competition involves institutional conflicts to a lesser extent than effects of distribution in the narrower meaning defined by Scharpf. That is, the creation of a uniform law on company tax would of course be combined with costs of adaptation for each individual member state, which are proportionally higher the less the respective national model can be implemented at the European level. Yet adapting the respective laws on company tax affects the cornerstones of the current economic model to a much lesser degree than, for example, EU-wide coordination of wage settlements. This applies especially to the harmonisation of the tax base; less so to tax rates. Because rates of taxation are essentially excluded here, distributional conflicts are restricted solely to the anticipated adaptation costs. If a common EU-wide basis of tax assessment existed, a further step forward could be the introduction of a 'range' or margin of permitted rates of taxation, as in the case of value added tax. As soon as this scenario looms, various viewpoints reemerge more prominently amongst the groups of countries. At least, an interpretation of the dissent concerning the procedural level of tax harmonisation is possible along these lines: It is on this basis that the Scandinavian social democrats support extending the majority principle to tax issues, though they categorically reject 
giving additional responsibilities to the commission. The converse applies in the Transition countries: here, responsibility for the commission is welcomed because it would increase the scope of interstate redistribution. In addition to the effects of distribution for specific groups of countries, it is crucial whether one is in government or with the opposition as far as tax policy is concerned. All proposals for harmonisation and transfer of responsibility meet with very little support from social democratic parties in government, and relatively broad support from parties in opposition.

With the exception of the Eurosceptic social democrats, a majority of respondents rate the Structural and Cohesion Policy (SCP) as good and effective. This is puzzling because the SCP has distinct interstate redistribution dimensions, and thus far we should expect the prevalence of national interests. Moreover, there is a relatively broad consensus on the new member states' access to the funds, even if this reduces the funding for old regions. ${ }^{10}$ The crucial difference in respect of harmonisation of social policy in the narrower sense is that the European SCP does not necessarily transform national welfare state institutions.

\section{Conclusion}

Evaluation of interviews with EU experts and leading personalities of the European left testifies primarily to the fact that opportunities for the creation of a common ESM at the European level are limited. At the level of problem perception and to the extent that policy proposals are sufficiently abstract, we find wide areas of common ground amongst the European social democratic parties. At the level of concrete measures, however, the differing interests of the member countries come to greater prominence, predominating over membership of the family of social democratic parties. The differing viewpoints can mainly be explained in terms of institutional and redistributional conflicts (see Appendix).

A distinction can be made between resolvable redistributional conflicts on the one hand, and institutional conflicts that can be overcome only with difficulty, even in the medium to long term, on the other hand. This is in line with our survey data: As examples of the latter, there was discussion in more detail on the proposal to introduce a minimum wage at the EU level, a coordinated wage and employment policy, and a coordinated fiscal and growth policy. These policies sensitively affect the institutional cornerstones of national welfare regimes more than merely redistributional EU initiatives. National politicians therefore fear not only the loss of power over policymaking, but also a reduction in the integrity and operability of the national welfare regime. These institutionally determined conflicts can only be solved with difficulty, even in the medium term, until there is convergence of the European welfare states.

With regard to the creation of a common EESM, all that seems conceivable is agreement at the European level on a catalogue of social fundamental rights ('a Europe of social rights'), or rather the further development of the social rights already contained in the draft constitution and the Social Charter.

Purely redistributional conflicts are easier to deal with than the institutional conflicts. In order to solve the former it is necessary to encourage the Eurosceptic members and the Transition countries to move in the direction of the groups of states characterised as Cohesion and Old Europe (see Table 2). One precondition for this is to note the 
redistributional share when we observe disagreement on EU policy proposals. There was detailed discussion about the example of tax base harmonisation. Although there are different tax systems at the national level, they are not as much core characteristics of welfare regimes as are wage or employment policies. Nevertheless, solving such conflicts is politically feasible: High-standard countries might compensate low-standard countries through the expansion of interstate redistribution systems for the sacrifices made for unattained competitive advantages, and, by way of compensation at the European level, effective barriers could be set up against competition that would result in undercutting.

Our study clearly confirms the impact of welfare state arrangements on preferences regarding European integration. We can obtain some insight into the struggle for a genuine European social policy if we distinguish between standard redistributional effects on the one hand and a more subliminal conflict due to competing levels of harmonisation on the other.

\section{References}

Boix, C. (1998) Political Parties, Growth and Equality. Conservative and Social Democratic Economic Strategies in the World Economy, New York: Cambridge University Press.

Budge, I. and Keman, H. (1990) Parties and Democracy. Coalition Formation and Government Functioning in Twenty States, Oxford: Oxford University Press.

Cameron, D.R. (1985) 'Does government cause inflation? Taxes, spending, and deficits', in L.N. Lindberg and C.S. Maier (Eds.) The Politics of Inflation and Economic Stagnation. Theoretical Approaches and International Case Studies, Washington: The Brookings Institution, pp.224-279.

Castles, F.G. and Mitchell, D. (1993) 'Worlds of welfare and families of nations', in F.G. Castles (Ed.) Families in Nations. Patterns of Public Policy in Western Democracies, Aldershot, Dartmouth: Kluwer, pp.93-128.

Daly, M. and Yeates, N. (2003) 'Common origins, different paths: adaptation and change in social security in Britain and Ireland', Policy and Politics, Vol. 31, No. 1, pp.85-97.

Dauderstädt, M. (2004) Conflicting Distributive Interests in a Deepening and Widening Europe. A Challenge to the Emerging Europolity, Bonn: Friedrich-Ebert-Stiftung, Europäische Politik.

Esping-Andersen, G. (1990) The Three Worlds of Welfare Capitalism, Cambridge: Polity Press.

Esping-Andersen, G. (1996) Welfare States Transition. National Adaptations in Global Economies, London et al.: Sage.

Goodin, R.E., Headey, B., Muffels, R.J.A. and Dirven, H-J. (1999) The Real Worlds of Welfare Capitalism, Cambridge: Cambridge University Press.

Hall, P.A. and Gingerich, D. (2004) 'Varieties of capitalism and institutional complementarities in the macroeconomy. An empirical analysis', MPIfG Discussion Paper 04/5.

Hall, P.A. and Soskice, D. (2001a) 'Introduction', in P.A. Hall and D. Soskice (Eds.) Varieties of Capitalism. The Institutional Foundations of Comparative Advantage, Oxford: Oxford University Press, pp.1-68.

Hall, P. and Soskice, D. (Eds.) (2001b) Varieties of Capitalism. The Institutional Foundations of Comparative Advantage, Oxford: Oxford University Press.

Hibbs, D. (1977) 'Political parties and macroeconomic policy', American Political Science Review, Vol. 71, No. 4, pp.1467-1487.

Hix, S. (1999) 'Dimensions and alignments in European union politics. Cognitive constraints and partisan responses', European Journal of Political Research, Vol. 35, No. 1, pp.69-125.

Hooghe, L. and Marks, G. (2004) European Integration and Democratic Competition, Bonn: Friedrich-Ebert-Stiftung, Europäische Politik. 
Hooghe, L., Marks, G. and Wilson, C. (2002) 'Does left/right structure party positions European integration?', Comparative Political Studies, Vol. 35, No. 8, pp.965-989.

Knell, M. and Srholec, M. (2006) 'Emerging varieties of capitalism in central and eastern Europe', in D. Lane and M. Myant (Eds.) Varieties of Capitalism in Post-Communist Countries, New York: Palgrave Macmillan (forthcoming).

Leibfried, S. (1991) 'Towards a European welfare state? On integrating poverty regimes into the European community', in Z. Ferge and J.E. Kolberg (Eds.) Social Policy in a Changing Europe, Frankfurt, Boulder: Campus/Westview, pp.245-280.

Marks, G. (2004) 'Conclusion: European integration and political conflict', in G. Marks and M.R. Steenbergen (Eds.) European Integration and Political Conflict, Cambridge: Cambridge University Press, pp.235-259.

Marks, G. and Steenbergen, M.R. (Eds.) (2004) European Integration and Political Conflict, Cambridge: Cambridge University Press.

McMenamin, I. (2004) 'Varieties of capitalism democracy: what difference does east-central Europe make?', Journal of Public Policy, Vol. 24, No. 3, pp.259-274.

O'Connor, J. (2005) 'Policy coordination, social indicators, and the social policy agenda in the European Union', Journal of European Social Policy, Vol. 15, No. 4, pp.345-361.

Petring, A. and Kellermann, C. (2005) New Options for a European Economic and Social Policy, Bonn: Friedrich-Ebert-Stiftung, Europäische Politik.

Scharpf, F.W. (1996) 'Negative and positive integration in the political economy of European welfare states', in G. Marks, F.W. Scharpf, P.C. Schmitter and W. Streeck (Eds.) Governance in the European Union, London: Sage, pp.15-39.

Scharpf, F.W. (2000) Interaktionsformen. Akteurszentrierter Institutionalismus in der Politikforschung, Opladen: Leske + Budrich.

Schmidt, M.G. (1983) 'The welfare state and the economy in periods of economic crisis. A comparative study of twenty-three OECD nations', European Journal of Political Research, Vol. 11, No. 1, pp.1-26.

\section{Bibliography}

Boldrin, M. and Canova, F. (2003) 'Regional policies and EU enlargement', in B. Funck and L. Pizzati (Eds.) European Integration, Regional Policy, and Growth, Washington, DC: The World Bank, pp.33-94.

Buti, M., Eijffinger, S. and Franco, D. (2003) 'Revisiting EMU's stability pact: a pragmatic way forward', Oxford Review of Economic Policy, Vol. 19, No. 1, pp.100-111.

Buti, M. and Nava, M. (2003) 'Towards a European budgetary system', Paper Prepared for the Annual Congress of the IIPF, http://www.iue.it/RSCAS/WP-Texts/03_08.pdf.

Büttner, T. (2006) 'Steuerwettbewerb und Finanzausgleich', ifo Schnelldienst, No. 4, pp.12-8.

Eurostat NewCronos (2004) VDR-Verband Deutscher Rentenversicherungsträger: Europa in Zeitreihen, Frankfurt am Main, http://www.sozialpolitik-aktuell.de/docs/VDR_Europa_in _Zeitreihen_2004.pdf.

Schmid, J. (2002) Wohlfahrtsstaaten im Vergleich, Opladen: Leske + Budrich.

Scruggs, L. and Allan, J. (2006) 'Welfare-state decommodification in 18 OECD-countries. A replication and revision', Journal of European Social Policy, Vol. 16, No. 1, pp.55-72. 


\section{Notes}

1 This study is based on a research project on the EESM conducted by the German Friedrich Ebert Stiftung. The surveyed countries were Austria, the Czech Republic, Denmark, Finland, France, Germany, Greece, Hungary, Ireland, Italy, the Netherlands, Poland, Portugal, the Slovak Republic, Spain, Sweden and the UK. For the questionnaire, findings relating to countries and the data set, see http://www.fes.de/internationalepolitik/.

2 See Petring and Kellermann (2005) on the development of questions related to and economic discussion of the EESM.

3 This line of argument assumes that distributional conflicts are enacted chiefly at interstate level, although a large proportion of the funds from the structural funds do not flow to states but to regions. Consequently, what is to be expected are redistributional conflicts between regions within a particular state. However, governments of member states sit at the negotiating table and therefore the interstate perspective is justified.

4 In 2005, both the Broad Economic Policy Guidelines (BEPG) and the European Employment Strategy (EES) were 'integrated' into the 'Integrated Guidelines for Growth and Employment 2005-2008'.

5 However, New Labour recently proposed a 'Globalisation Fund', which could be interpreted as a concept akin to anticyclical measures.

6 There was a dearth of concrete answers to the question on developing coordination between European workers' councils and national trade unions.

7 Strikingly, Italian social democrats can imagine both QMV in the Council of Ministers and the transfer of tax responsibilities to the EU Commission. Associated with this is the widespread vision within the Italian left of expanding the EU to become a federal state.

8 Even the Slovakian left expresses support, with greater reservations, for limits to tax competition through harmonisation of the basis of tax assessment, which could be achieved via the $\mathrm{OMC}$.

9 Although six of the 17 parties nevertheless express support for a short- or medium-term version of the 'broad economic guidelines' or 'Integrated Guidelines' (seven parties adopt no viewpoint), these are all parties in opposition except for the German SPD.

10 However, no clear majority is in favour of further increasing the budget of the SCP. 


\section{Appendix}

Social democratic parties and European social policy: common options/conflicting measures

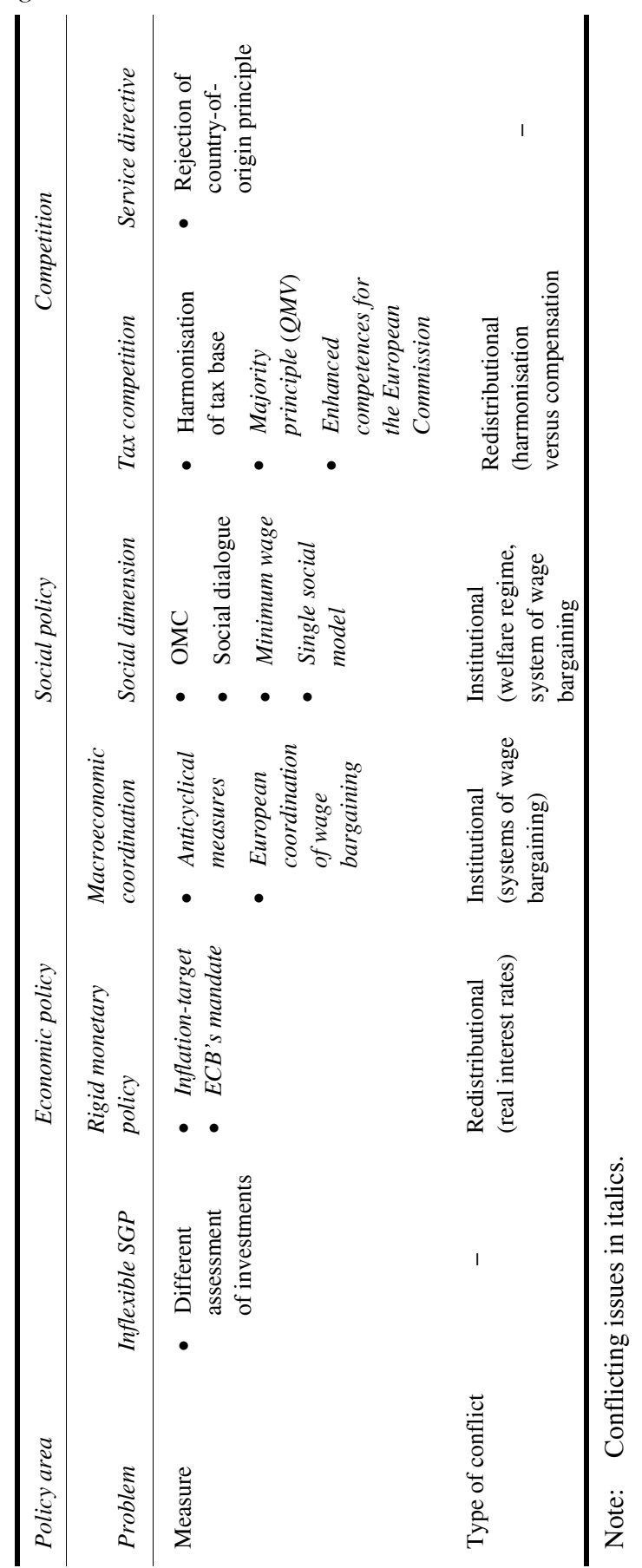

